\title{
Полиструктурность и полигенетичность островных геосистем
}

\author{
ГАНЗЕЙ К.С. \\ Федеральное государственное бюджетное учреждение науки \\ Тихоокеанский институт географии ДВО РАН, Владивосток \\ geo2005.84@mail.ru
}

\begin{abstract}
Аннотация. С 1970-х годов в отечественном ландшафтоведении начали активно развиваться идеи полигенетичности и полиструктурности ландшафтного пространства. Геосистемные особенности территории обусловлены сопряженным действием геофизических полей. В силу изолированного положения островных геосистем, их происхождения, площади и высоты результирующий итог действия геофизических полей имеет специфические, отличительные от континентальных районов черты. Они были раскрыты в рамках теории островного ландшафтоведения. На основе изучения ландшафтной организации Курильских, Гавайских островов и островов залива Петра Великого (Японское море) показаны особенности проявления и взаимодействия геостационарного, геоциркуляционного и биоциркуляционного геофизических полей на формирование полиструктурного и полигенетичного ландшафтного пространства островных геосистем. Ключевое место в процессе ландшафтной дифференциации на островах, как и на континентах, принадлежит геостационарному геофизическому полю. Но для островных геосистем оно определяет важнейшие ландшафтообразующие факторы - площадь и высоту суши. Для островных геосистем вулканически активных районов скорость восстановления ландшафтов после извержений наглядно проявляется через изменение показателей сложности ландшафтного рисунка, и, в первую очередь, через волновую динамику значений ландшафтного разнообразия. Принцип суперпозиции является ключевым и в процессе формирования биоты островной геосистемы. Изолированность, площадь и высота островной суши формируют уникальные черты растительного и животного мира. Островные геосистемы представляют собой сопряженное сочетание всех генетических разновидностей геосистем. Генезис, физические свойства и пространственное положение островных геосистем определяют их региональные особенности, а фундаментальные процессы функционирования остаются едиными вне зависимости от каких-либо факторов и обусловлены наличием свойств замкнутых географических систем.
\end{abstract}

Ключевые слова: островные геосистемы, замкнутые географические системы, Курильские острова, Гавайские острова, острова залива Петра Великого.

\section{Polystructurality and polygenetics of island geosystems}

\author{
GANZEI K.S. \\ Pacific Geographical Institute, FEB RAS, Vladivostok \\ geo2005.84@mail.ru
}

\begin{abstract}
Research into the nature and structure of polygenetic landscapes began in the 1970s and showed that the physical geography of landscapes results from the combined effects of multiple geophysical fields. Based on a comprehensive study of continental landscapes, spatial and temporal aspects of the multistructure and polygenetics of landscape space were revealed. Because islands are isolated, their origin, area and topography are distinct from continental areas. These distinctions have been revealed by studies of island landscapes. The peculiarities of manifestation and interaction of the geostationary, geocirculating and biocirculating geophysical fields result in the the formation of the polystructural and polygenetic landscapes of island geosystem. This is shown on the basis of research focused on landscape organization of the Kurile and Hawaiian Islands and those of Peter the Great Bay (the Sea of Japan). As on the
\end{abstract}


continents a key place in the process of landscape differentiation on the islands, belongs to the geostationary geophysical field. But for island geosystems, it determines the most important landscape-forming factors - the area and height of the land. The rate of landscape restoration after eruptions for island geosystems of volcanic active regions is clearly manifested through a change in the indicators of complexity of the landscape. First of all it is manifested through the wave dynamics of the values of landscape diversity. The key in the process of forming the biota of the island geosystems is due to the principle of superposition. The isolation, area and height of the island forms unique features of the flora and fauna. It is demonstrated that the island geosystems represent the combination of all genetic versions of geosystems. The genesis, physical properties and spatial location of island geosystems define their regional features, whereas the fundamental processes of functioning remain uniform and do not depend on any factors, but rather are caused by the presence of the properties of closed geographical systems.

Keywords: island geosystems, closed geographic systems, Kurile Islands, Hawaiian Islands, Peter the Great Bay Islands.

\section{Введение}

Вещественно-энергетическое взаимодействие в поверхностном слое Земли водных, воздушных, грунтовых и биотических масс обусловливает полигенез ландшафтов всех иерархических уровней. На основе комплексного изучения континентальных ландшафтов были раскрыты пространственные и временные аспекты полиструктурности и полигенетичности ландшафтного пространства [1-7 и др.]. Оценка и характер ландшафтного полигенеза выявляются при сопряженном изучении всех генетических разновидностей геосистем $[2,4,6]$.

Специфика проявления ландшафтообразующих процессов является определяющим фактором региональной ландшафтной дифференциации. Сопряженное функционирование геофизических полей (геостационарного, геоциркуляционного и биоциркуляционного) формирует отличительные геосистемные особенности территории. Наиболее отчетливо данный процесс фиксируется для бассейновых систем [8].

В отличие от континентальных территорий, ландшафтные изучения которых и были основой для раскрытия вопросов ландшафтного полигенеза, острова являются специфическими географическими образованиями, что находит свое отражение в теории островного ландшафтоведения, в первую очередь выраженные в эмпирических закономерностях ландшафтного строения данных объектов $[9,10]$. Островам как изолированным участкам суши свойственно сочетание элементов замкнутых географических систем, что определяет специфические черты ландшафтного полигенеза.

Представленные результаты исследований направлены на раскрытие особенностей проявления и взаимодействия геофизических полей в процессе существования и функционирования островных геосистем.

\section{Материалы и методы}

В качестве объекта исследований выступали острова северо-западной части Тихого океана - Курильские и Гавайские, острова залива Петра Великого, отличающиеся как по истории формирования, так и функционированию природных комплексов.

Курильские острова простираются от п-ова Камчатка до о-ва Хоккайдо почти на 1200 км и включают в себя более 30 островов и отдельно стоящих скал. Их складчатоглыбовая структура сформировалась в конце плиоцена - начале плейстоцена [11]. На Курильских островах представлены бореальные приокеанические (лесолуговые) ландшафты, переходные к субарктическим. Для них характерно искажение природной зональности в виде формирования более высокоширотных типов геосистем [12]. В состав Гавайев входит более 120 островов, рифов и скал. Основная площадь приходится на 8 островов [13]. Острова размещаются на южной оконечности Гавайско-Императорской разломной зоны [14]. На Гавайских островах развиты вулканогенные ландшафты тропического пояса зоны 
влажного климата с преобладанием лесной растительности [15]. В заливе Петра Великого (Японское море) расположено более 30 островов различной площади, из них наиболее крупные входят в состав архипелага Императрицы Евгении. Образование островов произошло 8-10 тыс. лет назад в результате медленного подъема уровня Японского моря [16]. На островах залива представлены дальневосточные бореальные и суббореальные среднеи южнотаежные притихоокеанские ландшафты с характерной муссонной циркуляцией воздушных масс [12].

Для всех рассматриваемых островов были выполнены ландшафтные исследования, включавшие в себя полевые работы (кроме Гавайских островов), дешифрирование данных дистанционного зондирования, средне- и крупномасштабное ландшафтное картографирование, качественный и количественных анализ сложности ландшафтной организации, оценена поствулканическая трансформация ландшафтов на Курильских и Гавайских островах.

\section{Результаты и их обсуждение}

Ведущая роль в формировании полиструктурности и полигенетичности геосистем принадлежит геостационарному геофизическому полю, которое по своей природе является геолого-геоморфологической основой ландшафта [6]. Это наглядно проявляется для всех островных геосистем в виде морфологической структуры ландшафта. При этом геостационарное поле имеет ключевое влияние на образование и функционирование островов океанического типа [15] в результате вулканических (острова-вулканы и острова, образованные при трещинных излияниях) и тектонических процессов (острова геосинклинальных зон).

Ландшафтные исследования Курильских и Гавайских островов отразили ведущее значение геостационарного поля в процесс ландшафтной дифференциации территории [17]. Активные геодинамические процессы, главным образом вулканизм, оказывают влияние не только на геолого-геоморфологическое строение территории, но и на региональную специфику проявления гео- и биоциркуляционных полей.

Отличительной особенностью вулканогенных геосистем является нарушение баланса вещества в высотных поясах ландшафтов. В горных районах баланс вещества имеет прямую зависимость от высоты и крутизны склонов. В вулканически активных районах данная закономерность нарушается. Происходит отклонение от географического распределения по высотным поясам рельефообразующего материала, где в приходной статье большое значение имеет поступление вещества эндогенного происхождения. При выбросе продуктов извержения происходит их аккумуляция на вершинах и склонах вулканических массивов, они часто не достигают предгорных и долинных ландшафтов. Под действием вулканизма максимальные положительные значения баланса вещества перемещаются в вершинную и склоновую часть вулканических массивов. Однако в периоды вулканического спокойствия ландшафты развиваются под действием комплекса экзогенных процессов и баланс вещества, свойственный невулканическим районам, начинает проявляться и здесь [18]. Вулканы Курильских и Гавайских островов, как и острова в целом, представляют собой ядерные хорионы [19]. Они оказывают существенное воздействие на структуру растительного и почвенного покровов. При извержении растительность подвергается комплексному механическому, тепловому и геохимическому воздействиям. На большинстве действующих вулканов нет растительного и почвенного покрова на ландшафтах стратовулканических конусов. Почвенный покров имеет слоистую структуру: многочленный профиль состоит из современного и погребенных слоев, что связано с периодическим выпадением вулканического материала. Воздействие продуктов извержения приводит к исчезновению ряда видов растений на островах-вулканах и на некоторых участках крупных островов. Асимметричное выпадение продуктов извержения вызывает экспозиционные различия в ландшафтных катенах. Они выражаются в нарушении структуры высотной по- 
ясности растительности и почвенного покрова. А на пониженных и равнинных участках выпадение вулканического пепла приводит к заболачиванию территории. Поступление продуктов извержения в атмосферу трансформирует биоклиматические характеристики территории [20]. На примере Курильских островов-вулканов установлено, что несмотря на коренную перестройку ландшафтов под действием вулканизма, геосистемы вулканически активных островных территорий в ходе эволюционного развития сформировали мощные механизмы устойчивости к вулканогенному влиянию. Такие свойства геосистем как самоорганизация и саморегуляция определяют запуск процесса интенсивного восстановления ландшафтной структуры территории в поствулканический период. Свойство саморегуляции, выраженное через адаптацию, сохраняет переменную структуру геосистем в вулканогенном серийном ряду развития при квазипериодическом влиянии продуктов извержения. Скорость восстановления ландшафтов островных геосистем после извержения наглядно проявляется через изменение показателей сложности ландшафтного рисунка, и, в первую очередь, через волновую динамику значений ландшафтного разнообразия (рис. 1) [20].

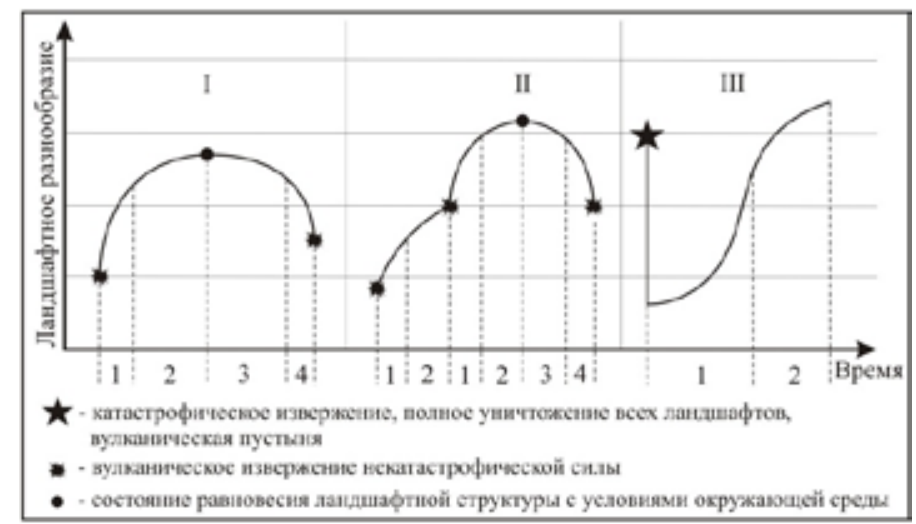

Рис. 1. Сценарии изменения ландшафтного разнообразия под действием вулканической активности [20]. Условные обозначения: Сценарии: I - поствулканическое восстановление ландшафтной структуры с достижением состояния равновесия с условиями окружающей среды; II - поствулканическое восстановление ландшафтной структуры, прерывающееся новым извержением; III - катастрофическое извержение с полным уничтожением существующих ландшафтов; $1-4$ - стадии изменения ландшафтного разнообразия

Fig. 1. Scenarios of landscape diversity changes under the influence of volcanic activity. Scenarios: I - postvolcanic restoration of the landscape structure with the achievement of equilibrium with environments; II - postvolcanic restoration of the landscape structure interrupted by the next eruption; III - catastrophic eruption resulting in complete destruction of the existing landscapes; $1-4-$ stages of landscape diversity changes

Полигенез островных вулканических геосистем проявляется в воздействии эндогенной энергии на термоэдафические условия их развития и функционирования. Наглядным примером является влк. Менделеева на Курильских островах. Выходы подземных парогазовых геотерм и сольфатар сформировали устойчивые условия развития бореальных ландшафтов с присутствием субтропических реликтовых видов растений. Ландшафты Курильских островов представляют собой зону первичного континентального ландшафтогенеза [7].

Происхождение материковых островов находится в тесной взаимосвязи с биоциркуляционным полем: в результате климатических флуктуаций, приводящих к разнонаправленным изменениям уровня Мирового океана, происходит либо изоляция или исчезновение, 
либо соединение островов с материком. Как уже отмечалось, острова залива Петра Великого образовались в результате подъема уровня моря, вызванного глобальными биоклиматическими изменениями географической оболочки.

В соответствии с классификацией островов [15] выделяется биогенный тип (острова атоллов, коралловых рифов), существование которого обусловлено биоклиматическими характеристиками экваториальных и тропических широт. Но базисом его формирования в любом случае является геостационарное поле в виде вершин подводных вулканов или горных массивов. Нельзя не упомянуть и о роли геоциркуляционного поля в формировании островов в результате однонаправленного нисходящего перемещения вещества в акваторию с образованием изолированных участков суши. Однако время их существования во многом определяется региональными и локальными гидродинамическими процессами.

Функционирование геостационарного поля определяет важнейшие факторы ландшафтной организации островных геосистем - площадь и высоту суши, что является основой формирования векторных геосистем, процессы в которых протекают под действием геоциркуляционного поля. Бесспорно, что на любом острове происходит формирование ландшафтных катен. Однако при уменьшении площади острова ниже определенной критической величины из ландшафтной структуры начинают «выпадать» векторные бассейновые геосистемы. Как отмечал А.Н. Иванов [10], это приводит к отсутствию долинных комплексов, изменению ландшафтного рисунка в целом, к падению ландшафтного разнообразия островных геосистем. Определение критической площади острова, ниже которой не происходит формирование системы поверхностного стока, является одной из важнейших фундаментальных задач физической географии. Для континентальных территорий существуют примеры работ по определению минимальной площади водосборного бассейна. Так, для территории юга Приморского края эта площадь составляет 0,65 км² $^{2}$. В более «влажных» в климатическом отношении условиях при равных (близких) высотах и уклонах, например, для островов Японского моря, аналогичный анализ, скорее всего, даст меньшую пороговую площадь [21]. Исходя из этого можно предположить, что для островов залива Петра Великого минимальная площадь водосбора будет схожей с континентальными районами или меньшей. Этот вывод должен быть подкреплен экспериментальными гидрологическими исследованиями.

Острова, являясь изолированными акваториями участками суши, окружены берегом. Представляя собой линейное образование, берег играет ключевую связующую роль между аквальными и аэральными комплексами, совокупность которых формирует береговую зону. По своему функционированию она не является векторной геосистемой, так как для нее характерно двухстороннее перемещение вещества и энергии. Береговая зона - это полигенетическое образование, сформированное действием всех геофизических полей: геостационарное поле - основа береговой зоны, геоциркуляционное - формирует гравитационные латеральные вещественно-энергетические связи, биоциркуляционное - обусловливает интенсивность и характер воздействия воды на береговую зону, поступление энергии и вещества с подводного берегового склона. Необходимо отметить, что для береговой зоны, как и для вулканических ландшафтов, отмечается нарушение баланса вещества, вызванное поступлением осадочных отложений под действием гидродинамических процессов. Только при условии сочетания всех процессов происходит формирование и функционирование береговой зоны. Именно здесь наиболее отчетливо проявляется принцип суперпозиции: совокупное действие геополей формирует системную целостность составляющих компонентов, определяющих структурное разнообразие ландшафтов.

Комплексное изучение наземных и подводных ландшафтов, с составлением единой классификации аэральных и аквальных ландшафтов о-ва Монерон [22] и островов залива Петра Великого [23], выявило существование территориально-акваториальных природных систем (ТАПС). При анализе пространственной организации ТАПС объективно выделяются зоны интенсивного и ослабленного взаимодействия суши и моря [22]. Например, на о-ве Шкота (залив Петра Великого) зону интенсивного взаимодействия форми- 


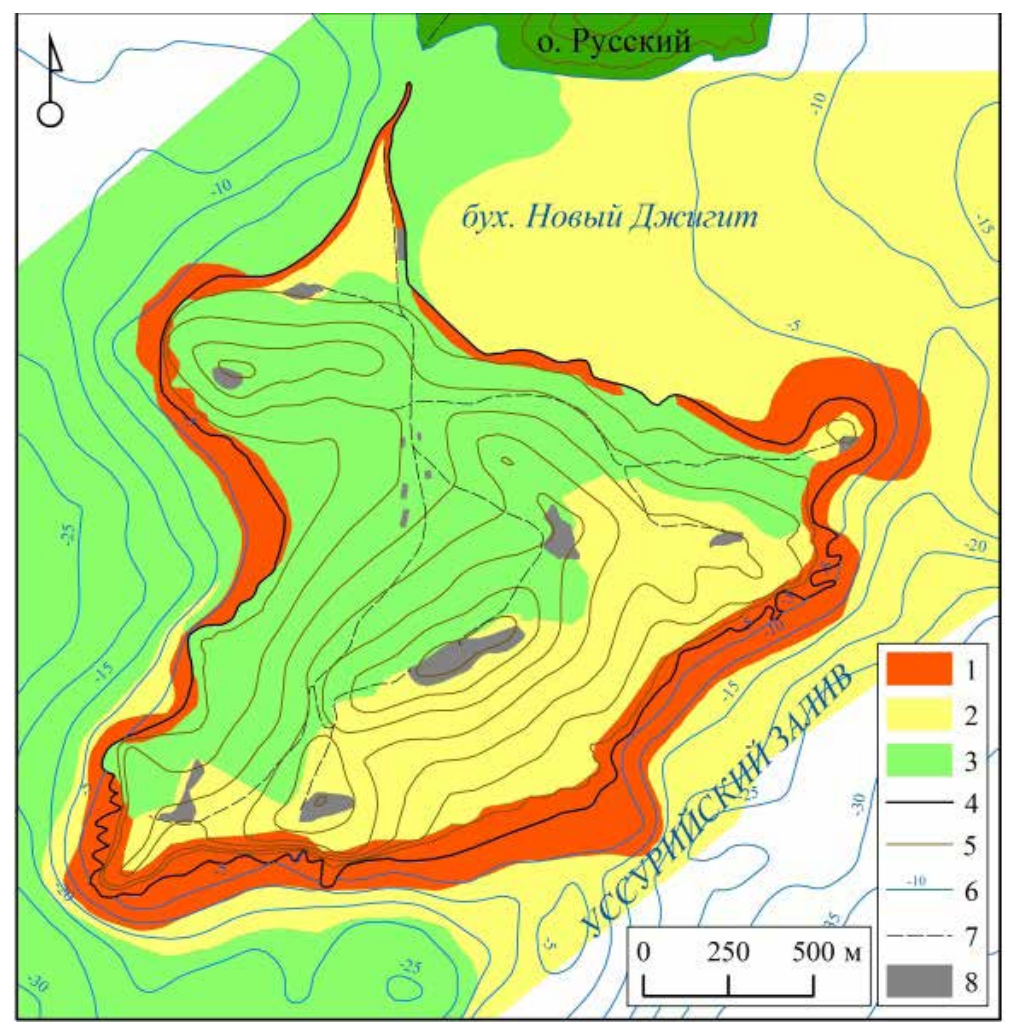

Рис. 2. Зона взаимодействия ландшафтов территориально-акваториальной природной системы о-ва Шкота [23]. Условные обозначения: зоны взаимодействия: 1 интенсивная; 2 - умеренная; 3 - ослабленная; 4 - линия берега; 5 - изогипсы (проведены через 20 м); 6 - изобаты с указанием глубины; 7 - дороги; 8 - селитебные территории

Fig 2. Zones of interaction of aerial and aquatic landscapes: 1 - intense, 2 - moderate, 3 -weakened; 4 - shoreline, 5 - isohypses (marking every $20 \mathrm{~m}$ ), 6 - isobaths indicating the depth, 7 - roads, 8 - residential areas

руют абразионно-денудационные и пляжевые аккумулятивные аэральные, абразионные и абразионно-аккумулятивные аквальные роды ландшафтов. Со стороны моря данная граница проходит примерно по изобате -10 м. Именно в зоне интенсивного взаимодействия формируется максимальное напряжение системообразующих и системосвязующих процессов ТАПС островов (рис. 2) [23].

Принцип суперпозиции находит отражение в действии биоциркуляционного геофизического поля. Наиболее наглядно это прослеживается на примере растительности и животного мира островов и объясняется в рамках равновесной теории островной биогеографии Мак-Артура - Уилсона [24]. Её суть заключается в том, что видовое разнообразие биоты на островах образуется в ходе случайного потока мигрирующих видов флоры и фауны, зависящего от степени изоляции и вероятности гибели вида. Таким образом, видовое разнообразие биоты на острове зависит от двух факторов - степени изоляции и площади [10]. Данные факторы также определяют уникальность флоры и фауны островов [24]. Типичным примером являются Гавайские острова - один из самых изолированных участков суши на Земле. Из 1700 видов сосудистых растений, 90-95 \% являются эндемиками [17].

Биоклиматическое формирование островных геосистем, как и континентальных, подчинено законам широтной зональности и высотной поясности. Однако, под действием циркуляционных процессов в прилегающих акваториях происходит существенное иска- 
жение широтных зон на островах. На Курильских островах влияние комплекса этих процессов и их воздействие на формирование воздушных масс определяют асимметричность распространения ландшафтных катен с теплолюбивыми формами растений. В результате ландшафтные катены с доминированием дубово-ольховых лесов с примесью клена и ильма приурочены исключительно к западному побережью о-ва Кунашир и о-ва Итуруп. Северная граница распространения дубово-ольховых лесов почти совпадает с окончанием ответвления теплого течения Соя, что обусловливает их максимальное проникновение на север до средней части о-ва Итуруп [26].

Установлено, что для экваториальных и тропических широт ландшафтообразующим фактором является региональная хронорганизация атмосферного увлажнения [10]. Например, на Гавайских островах под действием северных пассатов сухие леса распространены исключительно на подветренных юго-восточных склонах, влажные леса - на переувлажненных северо-восточных. Также климатические различия вызывают почвенную асимметрию. Для ландшафтных катен северо-восточных макросклонов характерны ультисоли - текстурно-дифференцированные почвы теплого, гумидного климата, для юго-западных макросклонов - аридисоли - слаборазвитые пустынные почвы [17]. Исследования почвенного покрова островных территорий отражают формирование особых типов почв с характерным морским гидротермически-импульверизационным режимом функционирования [10]. Для почв островов залива Петра Великого также характерны особенности «островного» почвообразования, обусловленные геохимическим влиянием моря, высотой, крутизной, экспозицией склонов и разнообразием растительности [25].

На островах возможно формирование орнитогенных геосистем. В результате жизнедеятельности колониальных птиц происходит механическое изменение верхней части литогенной основы, формирование специфического орнитогенного микрорельефа и почвенно-растительного комплекса, отличающегося от зонального, формируется аномальный химический состав поверхностных и грунтовых вод [10]. На Курильских островах данный эффект отмечен на о-ве Чиринкотан и о-вах Демина.

\section{Заключение и выводы}

Совокупное существование и действие геофизических полей определяют уникальность ландшафтной организации островных территорий. Ключевое место в ландшафтной дифференциации на островах, как и на континентах, принадлежит геостационарному геофизическому полю. Но для островных геосистем оно определяет важнейшие ландшафтообразующие факторы - площадь и высоту суши.

Составной частью островов является береговая зона, которая представляет собой единую ТАПС, формируется в результате взаимодействия всех геофизических полей. Именно в береговой зоне наиболее сильно проявляется принцип суперпозиции ландшафтной организации.

Принцип суперпозиции является ключевым и в процессе формирования биоты островной геосистемы. Изолированность, площадь и высота островной суши формирует уникальные черты растительного и животного мира. Циркуляционные процессы в акваториях и атмосфере оказывают существенное влияние на экспозиционную дифференциацию ландшафтных катен.

Островные геосистемы представляют собой сопряженное сочетание всех генетических разновидностей геосистем. Генезис, физические свойства и пространственное положение островных геосистем определяют их региональные особенности, но фундаментальные процессы функционирования остаются едиными вне зависимости от каких-либо факторов и обусловлены наличием свойств замкнутых географических систем.

Настоящее исследование поддержано грантом РНФ № 18-77-00001. 


\section{Литература}

1. Сочава В.Б. Введение в учение о геосистемах. Новосибирск: Наука, 1978. 320 с.

2. Солнцев В.Н. Системная организация ландшафтов. М.: Мысль, 1981.340 с.

3. Пузаченко Ю.Г. Приложение теории фракталов к изучению структуры ландшафтов // Изв. АН СССР. Серия геогр. 1997. № 2. С. 24-40.

4. Михеев В.С. Ландшафтный синтез географических знаний. Новосибирск: Наука, 2001. 216 с.

5. Дьяконов К.Н., Пузаченко Ю.Г. Теоретические положения и направления исследований современного ландшафтоведения // География, общество, окружающая среда. Т. 2. Функционирование и современное состояние ландшафтов. М.: Городец, 2004. С. 21-35.

6. Николаев В.А. К теории ландшафтного полигенеза // Вестн. Моск. ун-та. Сер. 5. География. 2006. № 6. C. 3-8.

7. Коломыц Э.Г. Тихоокеанский мегаэкотон Северной Есразии. Ч. 2: Экология островного вулканического ландшафта. Роли, США: Лулу Пресс, 2016. 303 с.

8. Корытный Л.М. Бассейновая концепция в природопользовании. Иркутск: Изд-во Института географии CO PAH, 2001. $163 \mathrm{c}$.

9. Дьяконов К.Н., Пузаченко Ю.Г. Теоретические вопросы островного ландшафтоведения // Горизонты географии. К 100-летию К.К. Маркова. М.: б.и., 2005. С. 14-17.

10. Иванов А.Н. Островная биогеография и островное ландшафтоведение: история формирования представлений и основные этапы развития // Вопр. истории естествознания и техники. 2016. Т. 37, № 4. С. 684-701.

11. Желубовский Ю.С., Прялухина А.Ф. Курильские острова. Стратиграфия // Геология СССР. М.: Недра, 1969. T. 31. C. $527-566$.

12. Исаченко А.Г., Шляпников А.А. Ландшафты. М.: Мысль, 1989. 505 с.

13. Atlas of Hawaii. Third ed. Honolulu: UH Press, 1998. 333 p.

14. Tilling R.I., Heliker C., Swanson D.A. Eruptions of Hawaiian volcanoes: past, present and future: U.S. Geol. Surv. General Inf. Product. 2010. Vol. 117. 63 p.

15. Игнатьев Г.М. Тропические острова Тихого океана. М.: Мысль, 1979. 268 с.

16. Лящевская М.С., Ганзей К.С. Реконструкция палеоусловий голоцена для островов залива Петра Великого (Японское море) // Пути эволюционной географии: материалы Всерос. науч. конф., посвященной памяти проф. А.А. Величко. М.: ИГ РАН, 2016. С. 496-500.

17. Ганзей К.С. Особенности проявления ландшафтообразующих процессов на Курильских и Гавайских островах // География и природные ресурсы. 2014. № 2. С. 132-139.

18. Никольская В.В. Дальний Восток. Очерк южной половины Дальнего Восток. Владивосток: ДВНЦ АН CCCP, $1962.214 \mathrm{c}$.

19. Ретеюм А.Ю. Земные миры. М.: Мысль, 1988. 268 с.

20. Ганзей К.С. Сценарии изменения ландшафтного разнообразия под действием вулканизма // Докл. Академии наук. 2015. Т. 461, № 3. С. 338-342.

21. Гарцман Б.И. Анализ геоморфологических условий формирования первичных водотоков на основе цифровых моделей рельефа // География и природные ресурсы. 2013. № 1. С. 136-147.

22. Иванов А.Н., Шаповалова К.О. Подходы к изучению территориально-акваториальных природных систем // Вестн. Моск. ун-та. Сер. 5. География. 1997. № 1. С. 53-56.

23. Ганзей К.С., Жариков В.В., Пшеничникова Н.Ф., Лебедев А.М., Киселева А.Г. Ландшафтная организация береговой геоструктуры острова Шкота (залив Петра Великого) // Геосистемы восточных районов России: особенности их структур и пространственного развития. Владивосток: ТИГ ДВО РАН, 2019. С. 52-59.

24. MacArthur R.H., Wilson E.O. The theory of island biogeography. Prinston: Prinston Univ. Press, USA, 1967. $203 \mathrm{p}$.

25. Пшеничников Б.Ф., Пшеничникова Н.Ф. Специфика формирования буроземов на островах залива Петра Великого (юг Дальнего Востока) // Вестн. ДВО РАН. 2013. № 5. С. 87-96.

26. Ganzei K.S. Some geo-botanic features of the Kurile Islands // Miscellanea Geographica Regional Studies on Development. 2015. Vol. 19, No. 2. P. 33-39.

\section{References}

1. Sochava, V.B. Introduction to the Study of Geosystems Nauka: Novosibirsk, USSR, 1978; 320 p. (In Russian)

2. Solntsev, V.N. Systemic Organization of Landscapes Mysl': Moscow, USSR, 1981; 340 p. (In Russian)

3. Puzachenko, Yu.G. Application of Fractal Theory to the Study of Landscape Structure. Izvestiya RAS, Geographic Series. 1997, 2. 24-40. (In Russian)

4. Mikheev, V.S. Landscape Synthesis of Geographical Knowledge Nauka: Novosibirsk, Russia, 2001; 216 p. (In Russian)

5. Dyakonov, K.N., Puzachenko, Yu.G. Theoretical Provisions and Directions of Research of Modern Landscape Science Geography, Society, Environment. In The Functioning and Current State of the Landscape Gorodets: Moscow, Russia, 2004, vol. II, 21-35 p. (In Russian) 
6. Nikolaev, V.A. To the Theory of Landscape Polygenesis. Moscow University Geography Bulletin. Seriya 5 Geografiya. 2006, 6, 3-8. (In Russian)

7. Kolomyts, E.G. Pacific Ocean Mega Ecotone of Northern Eurasia. Part II: Ecology of Insular Volcanic Landscape Lulu Press:Raleigh, North Carolina, USA, 2016, 303 p. (In Russian)

8. Korytny, L.M. Basin Concept in Nature Resources Use Publ. House of the Institute of Geography SB RAS: Irkutsk, Russia, 2001, 163 p. (In Russian)

9. Dyakonov, K.N., Puzachenko, Yu.G. Theoretical Issues of Island Landscape Science. Horizons of Geography. To the 100th anniversary of K.K. Markova. Gorodets: Moscow, Russia, 2005, 14-17 p. (In Russian)

10. Ivanov, A.N. Insular Biogeography and Island Landscape Studies: the History of Knowledge Formation and Key Development Stages. Voprosy Istorii Estestvoznaniia i Tekhniki. 2016, 37(4). 684-701. (In Russian)

11. Zhelubovsky, Yu.S., Pryalukhina, A.F. Kurile Islands. In Stratigraphy Geology of the USSR. Nedra: Moscow, USSR, 1969, 31, 527-566 p. (In Russian)

12. Isachenko, A.G., Shlyapnikov, A.A. Landscapes Mysl’: Moscow, USSR, 1989, 505 p. (In Russian)

13. Atlas of Hawaii. Third ed. UH Press: Honolulu, USA, 1998, 333 p.

14. Tilling, R.I., Heliker, C., Swanson, D.A. Eruptions of Hawaiian volcanoes: past, present and future. U.S. Geol. Surv. General Inf. Product. 2010, 117, 63.

15. Ignat'ev, G.M. Tropical Islands of the Pacific Ocean. Mysl': Moscow, USSR, 1979, 268 p. (In Russian)

16. Lyashchevskaya, M.S., Ganzey, K.S. Reconstruction Of The Holocene Paleoenvironment in the Islands of the Peter the Great Bay (Sea of Japan). In Routes of Evolutionary Geography: Proceedings of the Scientific Conference in memory of professor A.A. Velichko (Moscow, November 23-25, 2016). Institute of Geography RAS: Moscow, Russia, 2016, 496-500 p. (In Russian)

17. Ganzei, K.S. Characteristics of the Manifestation of Landscape-Forming Processes in the Kurile and Hawaiian Islands. Geography and Natural Resources. 2014, 35(2), 181-187. (In Russian)

18. Nikol'skaya, V.V. Far East. Sketch of the Southern Half of the Far East Far East Scientific Center of AN USSR: Vladivostok, USSR, 1962, 214 p. (In Russian)

19. Reteum, A.Y. Earth Worlds Mysl': Moscow, USSR, 1988, 268 p. (In Russian)

20. Ganzei, K.S. Scenarios of Landscape Diversity Changes in Response to Volcanic Activity. Doklady Earth Sciences. 2015, 461(1), 312-315.

21. Gartsman, B.I. Analysis of Geomorphological Conditions for Primary Streams Formation Using Digital Elevation Models. Geography and Natural Resources. 2013, 34(1), 69-78.

22. Ivanov, A.N., Shapovalova, K.O. Approaches to the Studies on Territorial-Aquatorial Natural Systems (Moneron Island Case Study). Moscow University Geography Bulletin. Seriya 5 Geografiya. 1997, 1, 53-56. (In Russian)

23. Ganzei, K.S., Zharikov, V.V., Pshenichnikova, N.F., Lebedev, A.M., Kiselyova, A.G., Pyanov, A.A. Landscape Organization of the Coastal Geostructure of the Island Shkota (Peter the Greate Bay). In Geosystems of the Eastern Regions of Russia: the Features of Their Structures and Spatial Development. Pacific Geographical Institute of FEB RAS: Vladivostok, Russia, 2019, 52-59 p. (In Russian)

24. MacArthur, R.H., Wilson, E.O. The theory of island biogeography. Prinston Univ. Press: Prinston, USA, 1967, $203 \mathrm{p}$.

25. Pshenichnikov, B.F., Pshenichnikova, N.F. The Specifics of the Formation of Burozems on the Islands of Peter the Great Bay (South of the Far East). Vestnik of the Far Eastern Branch of Russian Academy of Sciences. 2013, 5, 87-96. (In Russian)

26. Ganzei, K.S. Some geo-botanic features of the Kurile Islands. Miscellanea Geographica-Regional Studies on Development. 2015, 19(2), 33-39. 